\title{
Effectiveness of flexible sigmoidoscopy screening in men and women and different age groups: pooled analysis of randomised trials
}

\author{
Øyvind Holme, ${ }^{1,2}$ Robert E Schoen, ${ }^{3}$ Carlo Senore, ${ }^{4}$ Nereo Segnan, ${ }^{4}$ Geir Hoff,,, 6 Magnus Løberg, 2,8 \\ Michael Bretthauer, ${ }^{1,2,7,8}$ Hans-Olov Adami, ,7,9 Mette Kalager2,7,8
}

'Department of Medicine, Sorlandet Hospital Kristiansand, Kristiansand, Norway

${ }^{2}$ Clinical Effectiveness Research group, Institute of Health and Society, University of Oslo, Oslo, Norway

3Departments of Medicine and Epidemiology, University of Pittsburgh, University of

Pittsburgh Cancer Institute,

Pittsburgh, PA

${ }^{4}$ Centro di Prevenzione

Oncologica Piemonte and Città della Salute e della Scienza

University Hospital, Turin, Italy

${ }^{5}$ Telemark Hospital Skien, Skien, Norway

${ }^{6}$ Cancer Registry of Norway,

Oslo, Norway

${ }^{7}$ Department of Epidemiology, Harvard TH Chan School of

Public Health, Boston, MA, USA

${ }^{8}$ Department of Transplantation Medicine and KG Jebsen Center for Colorectal Cancer Research, Oslo University Hospital, Oslo,

Norway

${ }^{9}$ Department of Medical

Epidemiology and Biostatistics, Karolinska Institutet, Stockholm, Sweden

Correspondence to: $\varnothing$ Holme oyvind.holme@medisin.uio.no Additional material is published online only. To view please visit the journal online.

Cite this as: $B M J$ 2017;356:16673 http://dx.doi.org/10.1136/bmj.i6673

Accepted: 04 December 2016

\section{ABSTRACT}

OBJECTIVE

To compare the effectiveness of flexible

sigmoidoscopy in screening for colorectal cancer by patient sex and age.

\section{DESIGN}

Pooled analysis of randomised trials (the US Prostate, Lung, Colorectal and Ovarian cancer screening trial (PLCO), the Italian Screening for Colon and Rectum trial (SCORE), and the Norwegian Colorectal Cancer Prevention trial (NORCCAP)).

\section{DATA SOURCES}

Aggregated data were pooled from each randomised trial on incidence of colorectal cancer and mortality stratified by sex, age at screening, and colon subsite (distal $v$ proximal).

\section{ELIGIBILITY CRITERIA FOR SELECTING STUDIES} Invited individuals aged 55-74 (PLCO), 55-64 (SCORE), and 50-64 (NORCCAP). Individuals were randomised to receive flexible sigmoidoscopy screening once only (SCORE and NORCCAP) or twice (PLCO), or receive usual care (no intervention).

\section{RESULTS}

287928 individuals were included in the pooled analysis; 115139 randomised to screening and 172789 to usual care. Compliance rates were $58 \%, 63 \%$, and $87 \%$ in SCORE, NORCCAP, and PLCO, respectively. Median follow-up was 10.5 to 12.1 years. Screening reduced the incidence of colorectal cancer in men (relative risk $0.76 ; 95 \%$ confidence interval 0.70 to 0.83 ) and women (0.83; 0.75 to 0.92$)$. No difference in the effect of screening was seen between men younger than 60 and those older than 60 . Screening reduced the incidence of colorectal cancer in women younger than 60 (relative risk 0.71; 95\% confidence interval

\section{WHAT IS ALREADY KNOWN ON THIS TOPIC?}

Flexible sigmoidoscopy screening has been shown to reduce incidence and

mortality from colorectal cancer in randomised trials

The effectiveness of such screening by age and sex is unknown

\section{WHAT THIS STUDY ADDS}

Aggregated data from three large scale randomised trials showed a difference in the effect of screening between the sexes; flexible sigmoidoscopy screening reduces incidence of colorectal cancer in men, and in women younger than 60

In women aged 60 and over, incidence of colorectal cancer was not reduced by screening, possibly because of increased prevalence of cancers in the proximal colon in older women

Other screening modalities that more effectively detect proximal tumours should be considered in older women

0.59 to 0.84$)$, but not significantly in those aged 60 or older $(0.90 ; 0.80$ to 1.02$)$. Colorectal cancer mortality was significantly reduced in both younger and older men, and in women younger than 60 . Screening reduced colorectal cancer incidence to a similar extent in the distal colon in men and women, but there was no effect of screening in the proximal colon in older women with a significant interaction between sex and age group $(P=0.04)$.

\section{CONCLUSION}

Flexible sigmoidoscopy is an effective tool for colorectal cancer screening in men and younger women. The benefit is smaller and not statistically significant for women aged over 60; alternative screening methods that more effectively detect proximal tumours should be considered for these women.

\section{Introduction}

Colorectal cancer is the third most frequently occurring cancer worldwide, ${ }^{1}$ and screening has been implemented in many countries. In four large scale randomised trials, flexible sigmoidoscopy screening has been shown to reduce both incidence and mortality from colorectal cancer, ${ }^{2-5}$ and one meta-analysis has shown consistent effects across the trials, with similar length of follow-up. ${ }^{6}$ Flexible sigmoidoscopy visualises only the distal part of colon. To partly overcome this limitation, individuals with pathological findings in the distal colon are referred for colonoscopy, because they might have clinically significant pathology in the proximal colon. ${ }^{7-9}$

The effect of flexible sigmoidoscopy screening in younger versus older individuals and in women versus men is currently unknown. There are reasons to believe that the effectiveness might differ in men and women. Women have proximal advanced neoplasia without a distal adenoma more frequently than men, which could trigger referral for colonoscopy. ${ }^{1011}$ Furthermore, in past decades, there has been a proximal shift in the localisation of colorectal cancer that appears more pronounced in women than men, especially among older women. ${ }^{12-15}$ Thus, the effectiveness of flexible sigmoidoscopy screening might be small or negligible in older women. If this hypothesis is confirmed, screening recommendations for colorectal cancer might need to be reconsidered.

To investigate the impact of sex and age on the effectiveness of flexible sigmoidoscopy screening, we launched a collaboration between the investigators of three of the four large scale randomised trials..$^{3-5}$ We merged aggregated data and conducted a pooled analysis of subgroups for sex and age. 


\section{Methods}

We examined data from three trials: the US Prostate, Lung, Colorectal and Ovarian cancer screening trial (PLCO), the Italian Screening for COlonREctum trial (SCORE), and the NORwegian Colorectal CAncer Prevention trial (NORCCAP). ${ }^{3-5}$ We invited the investigators of a fourth large scale flexible sigmoidoscopy screening trial (the UK Flexi Scope trial) to participate, but they declined. ${ }^{2}$ Data from a fifth flexible sigmoidoscopy screening trial, the Telemark Polyp Study, were not included owing to the trial's small size (799 enrolled individuals). Accordingly, data from $60 \%$ of control participants and $67 \%$ of screening participants of all flexible sigmoidoscopy screening trials were available for analyses.

\section{PLCO}

The flexible sigmoidoscopy screening part of the PLCO trial included individuals aged $55-74^{4}$ who were invited by post. Individuals were enrolled between 1993 and 2001 at 10 screening centres in the USA. Exclusion criteria were a history of prostate, lung, ovarian, or colorectal cancer; ongoing treatment for any type of cancer except basal cell or squamous cell skin cancer; or a history of lower endoscopy in the previous three years (beginning in 1995). Those who accepted the invitation were randomised to flexible sigmoidoscopy at inclusion and after three to five years, or to usual care (with no organised screening). Compliance with the first screen was $83.5 \%$, and $86.6 \%$ of participants underwent at least one screening examination. A positive screening test was defined as any lesion or mass that was detected during sigmoidoscopy, and all individuals with a positive test were referred to their primary care physician for further investigation, of which $95.6 \%$ included a colonoscopy. Colorectal cancer was defined as adenocarcinoma or carcinoid in the colon or rectum. Cancers were ascertained through questionnaires that were mailed annually, and all were verified through medical records. The trial is registered at clinicaltrials.gov (NCT00002540).

\section{SCORE}

The SCORE investigators invited individuals aged 55-64 in six regions of Italy between 1995 and 1999. ${ }^{5}$ Exclusion criteria were a history of colorectal cancer, adenomas, inflammatory bowel disease, having had a lower endoscopy within the previous two years, two or more first degree relatives with colorectal cancer, or a medical condition that precluded a possible benefit from screening. Individuals who accepted the invitation were randomised to once only flexible sigmoidoscopy, or to usual care (no screening). Compliance with screening was $58.3 \%$. A positive screening test was defined as colorectal cancer, any polyp that was greater than $5 \mathrm{~mm}$ in diameter, three or more adenomas, or any adenoma with high grade dysplasia or villous histology. Screened patients who tested positive were referred for colonoscopy at the screening centres. Colorectal cancer was defined as adenocarcinoma in the colon or rectum. Cases of colorectal cancer were ascertained by periodic linking of the trial database to the hospital discharge records and databases of the pathology departments. Blinded experts from the local cancer registries reviewed the candidate colorectal cancer cases. The trial is registered at isrctn.gov (ISRCTN27814061).

\section{NORCCAP}

Between 1999 and 2001, individuals aged 50-64 living in two areas of Norway were identified through the Population Registry. ${ }^{3}$ A personal history of colorectal cancer was the only exclusion criterion. A random sample of people was offered once only flexible sigmoidoscopy or the combination of once only flexible sigmoidoscopy and once only immunochemical testing for faecal occult blood (FlexSure OBT, Beckman-Coulter). The remaining population aged 50-64 who lived in the same areas served as controls and were not offered screening. Compliance with screening was $63 \%$. A positive screening test (defined as colorectal cancer, any adenoma, a polyp with diameter $10 \mathrm{~mm}$ or greater, or a positive faecal immunochemical test) qualified for colonoscopy referral at the screening centres. Colorectal cancer was defined as adenocarcinoma in the colon or rectum. Data were extracted by linking the participants' national identity numbers to the nationwide Norwegian Cancer Registry. The trial is registered at clinicaltrials.gov (NCT00119912).

\section{Aggregated analyses}

The investigators of the three trials provided aggregated data stratified by sex and age (in 5 year age groups), the number of individuals at risk, and the number of events (colorectal cancer cases and deaths) for each year of follow-up. From the three groups, we collected data on compliance with screening, follow-up colonoscopy, quality of bowel cleansing, and insertion depth during screening. The a priori primary outcome of the present study was to determine the incidence of colorectal cancer in the distal and proximal colon by sex and age group. Mortality due to distal or proximal colorectal cancer by sex and age group was the secondary outcome. We chose this approach to optimise power in the analyses (the event ratio of colorectal cancer cases to deaths was about 4:1). The distal colon was defined as the rectum and sigmoid, while the proximal colon was defined as the colon proximal to the sigmoid descending junction. Patients provided written, informed consent in the context of each trial (only screening attenders in NORCCAP). No new consent was obtained for the pooled analysis.

\section{Statistics}

Data were extracted from the databases used in the most recent publications. Data from the PLCO trial differed somewhat from those previously published, ${ }^{4}$ owing to the withdrawal of consents and updating of the trial database. We performed pairwise comparisons (stratified by sex and age group) of flexible sigmoidoscopy screening versus no screening using a Mantel-Haenszel fixed effects model and report relative risks with 95\% confidence intervals and forest plots. We applied a 
random effects model in a sensitivity analysis, and the results were comparable. Heterogeneity $\left(\mathrm{I}^{2}\right)$ was assessed according to recommendations from the Cochrane Collaboration: $0-30 \%=$ might not be important, 30-50\%=moderate heterogeneity, 50-75\%=substantial heterogeneity, $75-100 \%=$ considerable heterogeneity. ${ }^{16}$

We also constructed standardised cumulative risk plots using the screening group as the standard. The risk per year of follow-up was calculated as the number of colorectal cancer cases or deaths during that year divided by the mean number of people at risk for the same year. In the primary analyses, we included data for individuals aged 50-74 and stratified the analyses according to sex and age at screening ( $<60$ years $v \geq 60$ years).

We performed sensitivity analyses of the 55-64 year age group only because this was the age range covered by all three trials. We also analysed the data after extending the definition of distal colon to include the descending colon. To explore the impact of compliance with screening and the quality of the examination (screening flexible sigmoidoscopy and follow-up colonoscopy), we included compliance, bowel cleansing, and insertion depth at screening, and colonoscopy referral rate in univariate random effect metaregression models. The caecum intubation rate for colonoscopy examinations was not available for all trials.

To assess the heterogeneity between sex and age groups, we also included an interaction term between sex and age group and performed a multivariate metaregression analysis. Using the metareg program ${ }^{17}$ in Stata, we weighted the regression model to include variance within the study as well as residual variance between trials. Because the stratified data in the metaregression model were extracted from the same trials, we included indicator variables for the different trials in the regression model in addition to sex, age group, and the interaction term. All analyses were conducted with Stata 13.0 software (StataCorp) and Review Manager software version 5.2 (Nordic Cochrane Centre, Cochrane Collaboration). $\mathrm{P}<0.05$ was considered statistically significant and all analyses were by intention to treat.

\section{Patient involvement}

No patients were involved in setting the research question or the outcome measures, nor were they involved in developing plans for design or implementation of the study. No patients were asked to advise on interpretation or writing up of results. There are no plans to disseminate the results of the research to study participants or the relevant patient community.

\section{Results}

Altogether, the three trials comprised 115139 individuals randomised to screening and 172789 individuals randomised to usual care; 144846 (50.3\%) were women and 143082 (49.7\%) were men. Median follow-up in the three trials was 10.5 to 12.1 years. Trial characteristics are displayed in table 1 , and procedural characteristics in web tables 1 and 2.

\section{Incidence of colorectal cancer}

A total of 1494 individuals in the screening group were diagnosed with colorectal cancer, compared with 2663 in the control group. This corresponds to a risk reduction of 21\% (relative risk 0.79; $95 \%$ confidence interval 0.74 to 0.84 ), with no heterogeneity between the trials $\left(\mathrm{I}^{2}=0 \%, \mathrm{P}=0.67\right.$; figs $\left.1-5\right)$.

In men, incidence of colorectal cancer in the entire colorectum fell by $24 \%$ (relative risk 0.76 ; $95 \%$ confidence interval 0.70 to 0.83 ), with no difference between the age groups (table 2). In women, colorectal cancer incidence was reduced by $17 \%$ ( $0.83 ; 0.75$ to 0.92$)$. This effect was confined to the younger women $(0.71 ; 0.59$ to 0.84), while women 60 years and older had a small, statistically non-significant effect of screening (0.90; 0.80 to 1.02 ; table 2).

Our a priori assumption was that the reduced effectiveness of flexible sigmoidoscopy screening in older women might be caused by limited effect in the proximal colon. Accordingly, we performed stratified analyses by subsite.

For colorectal cancer incidence in the distal colon, the effectiveness of flexible sigmoidsocopy screening was similar in men and women, and in the age group younger than 60 compared with the age group of 60 and over (table 2, fig 6).

The incidence of proximal colorectal cancer was significantly reduced in men (relative risk 0.83 ; $95 \%$ confidence interval 0.73 to 0.94 ; fig 4 ), but not in women (0.91; 0.79 to 1.03; fig 5; $\mathrm{P}=0.04$ for interaction). In men, there was no apparent difference in the effectiveness of screening across the age groups (heterogeneity $\mathrm{I}^{2}=0 \%$; fig 4). There was moderate heterogeneity $\left(\mathrm{I}^{2}=33 \%\right.$, $\mathrm{P}=0.16)$ between the studies when the results for all women were pooled (fig 5). The heterogeneity disappeared completely when data for women younger and older than 60 years were pooled separately $\left(\mathrm{I}^{2}=0 \%\right.$ for

\begin{tabular}{|c|c|c|c|c|c|c|c|}
\hline Study & Population & Intervention & $\begin{array}{l}\text { Period of } \\
\text { inclusion }\end{array}$ & $\begin{array}{l}\text { Age group } \\
\text { (years) }\end{array}$ & $\begin{array}{l}\text { No of screened } \\
\text { participants/controls }\end{array}$ & $\begin{array}{l}\text { No of men/ } \\
\text { women }\end{array}$ & $\begin{array}{l}\text { Follow-up } \\
\text { (years, median)* }\end{array}$ \\
\hline PLCO† & $\begin{array}{l}\text { Volunteers at } 10 \text { screening } \\
\text { centres in the USA }\end{array}$ & $\begin{array}{l}\text { Flexible sigmoidoscopy at } \\
\text { inclusion and after 3-5 years }\end{array}$ & $1993-2001$ & $55-74$ & $77431 / 77433$ & $76670 / 78194$ & $11.9,12.1$ \\
\hline SCORE & Volunteers in six regions in Italy & Once only flexible sigmoidoscopy & 1995-99 & $55-64$ & $17136 / 17136$ & $17221 / 17051$ & $10.5,11.4$ \\
\hline NORCCAP & $\begin{array}{l}\text { Identified through Population } \\
\text { Registry in two regions in Norway }\end{array}$ & $\begin{array}{l}\text { Once only flexible sigmoidoscopy. } \\
50 \% \text { also provided FIT }\end{array}$ & $1999-2001$ & $50-64$ & $20572 / 78220$ & $49191 / 49601$ & 10.9 \\
\hline
\end{tabular}




\begin{tabular}{|c|c|c|c|c|c|c|}
\hline \multirow[b]{2}{*}{ Study } & \multicolumn{2}{|c|}{ No of events/total } & \multirow{2}{*}{\multicolumn{2}{|c|}{$\begin{array}{c}\text { Risk ratio (fixed, } \\
\mathrm{M}-\mathrm{H}, 95 \% \mathrm{CI} \text { ) }\end{array}$}} & \multirow[b]{2}{*}{$\begin{array}{l}\text { Weight } \\
\text { (\%) }\end{array}$} & \multirow[b]{2}{*}{$\begin{array}{l}\text { Risk ratio (fixed, } \\
\mathrm{M}-\mathrm{H}, 95 \% \mathrm{CI} \text { ) }\end{array}$} \\
\hline & Screening & Usual care & & & & \\
\hline PLCO 55-74 years & $990 / 77431$ & $1271 / 77433$ & + & & 61.7 & $0.78(0.72$ to 0.85$)$ \\
\hline SCORE 55-64 years & $251 / 17136$ & $306 / 17136$ & & & 14.9 & $0.82(0.70$ to 0.97$)$ \\
\hline NORCCAP 50-54 years & $40 / 6920$ & $315 / 37131$ & & & 4.8 & $0.68(0.49$ to 0.95$)$ \\
\hline NORCCAP 55-64 years & $213 / 13652$ & $771 / 41089$ & & & 18.7 & $0.83(0.72$ to 0.97$)$ \\
\hline Total $(95 \% \mathrm{Cl})$ & $1494 / 115139$ & $2663 / 172789$ & $\phi$ & & & \\
\hline \multicolumn{3}{|c|}{ Test for heterogeneity: $\chi^{2}=1.54, d f=3, P=0.67, I^{2}=0 \%$} & & & 100.0 & $0.79(0.74$ to 0.84$)$ \\
\hline \multirow{2}{*}{\multicolumn{3}{|c|}{ Test for overall effect: $z=7.10, P<0.001$}} & $0.5 \quad 0.7$ & 1.5 & 2 & \\
\hline & & & $\begin{array}{l}\text { Favours } \\
\text { screening }\end{array}$ & $\begin{array}{r}\text { Favou } \\
\text { usual ca }\end{array}$ & & \\
\hline
\end{tabular}

Fig 1 | Colorectal cancer incidence in the three trials comparing flexible sigmoidoscopy screening with usual care. Data from the NORCCAP trial are presented as two separate trials because the control: screening participants ratio was higher in the 50-54 year age group (5.4:1) than the 55-64 year age group (3:1). $\mathrm{M}-\mathrm{H}=$ Mantel-Haenszel fixed effect model

\begin{tabular}{|c|c|c|c|c|c|c|}
\hline \multirow{3}{*}{$\begin{array}{l}\text { Study } \\
\text { NORCCAP 50-54 years }\end{array}$} & \multicolumn{2}{|c|}{ No of events/total } & \multirow{2}{*}{\multicolumn{2}{|c|}{$\begin{array}{l}\text { Risk ratio (fixed, } \\
\mathrm{M}-\mathrm{H}, 95 \% \mathrm{Cl} \text { ) }\end{array}$}} & \multirow[b]{2}{*}{$\begin{array}{c}\text { Weight } \\
\text { (\%) }\end{array}$} & \multirow[b]{2}{*}{$\begin{array}{l}\text { Risk ratio (fixed, } \\
\mathrm{M}-\mathrm{H}, 95 \% \mathrm{Cl} \text { ) }\end{array}$} \\
\hline & Screening & Usual care & & & & \\
\hline & $10 / 3450$ & $105 / 18806$ & & & 4.9 & 0.52 (0.27 to 0.99$)$ \\
\hline PLCO 55-59 years & $55 / 12384$ & $87 / 12367$ & & & 13.1 & 0.63 (0.45 to 0.88$)$ \\
\hline NORCCAP $55-59$ years & $26 / 3762$ & $124 / 11179$ & & & 9.4 & 0.62 (0.41 to 0.95$)$ \\
\hline SCORE 55-59 years & $53 / 4800$ & $57 / 4925$ & & & 8.5 & 0.95 (0.66 to 1.38$)$ \\
\hline PLCO 60-64 years & $89 / 12010$ & $129 / 12012$ & $=$ & & 19.4 & $0.69(0.53$ to 0.90$)$ \\
\hline SCORE 60-64 years & $43 / 3767$ & $54 / 3729$ & & & 8.2 & 0.79 (0.53 to 1.17$)$ \\
\hline NORCCAP 60-64 years & $39 / 3057$ & $139 / 8937$ & & & 10.7 & $0.82(0.58$ to 1.17$)$ \\
\hline PLCO 65-69 years & $78 / 8877$ & $109 / 8887$ & & & 16.4 & 0.72 (0.54 to 0.96$)$ \\
\hline PLCO 70-74 years & $40 / 5065$ & $63 / 5068$ & 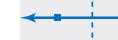 & & 9.5 & $0.64(0.43$ to 0.94$)$ \\
\hline Total $(95 \% \mathrm{Cl})$ & $433 / 57172$ & $867 / 85910$ & $\leftrightarrow$ & & & \\
\hline \multicolumn{4}{|c|}{ Test for heterogeneity: $\chi^{2}=5.42, \mathrm{df}=8, \mathrm{P}=0.71, \mathrm{I}^{2}=0 \%$} & & 100.0 & $0.71(0.63$ to 0.80$)$ \\
\hline \multirow{2}{*}{\multicolumn{3}{|c|}{ Test for overall effect: $z=5.62, P<0.001$}} & 0.50 .7 & 1.5 & 2 & \\
\hline & & & $\begin{array}{l}\text { Favours } \\
\text { screening }\end{array}$ & & & \\
\hline
\end{tabular}

Fig 2 | Colorectal cancer incidence in the distal colon (rectum and sigmoid colon) in men, based on data from the three trials comparing flexible sigmoidoscopy screening with usual care. $\mathrm{M}-\mathrm{H}=$ Mantel-Haenszel fixed effect model

\begin{tabular}{|c|c|c|c|c|c|c|}
\hline \multirow{3}{*}{$\begin{array}{l}\text { Study } \\
\text { NORCCAP 50-54 years }\end{array}$} & \multicolumn{2}{|c|}{ No of events/total } & \multirow{2}{*}{\multicolumn{2}{|c|}{$\begin{array}{l}\text { Risk ratio (fixed, } \\
\mathrm{M}-\mathrm{H}, 95 \% \mathrm{Cl} \text { ) }\end{array}$}} & \multirow[b]{2}{*}{$\begin{array}{c}\text { Weight } \\
(\%)\end{array}$} & \multirow[b]{2}{*}{$\begin{array}{c}\text { Risk ratio (fixed, } \\
\mathrm{M}-\mathrm{H}, 95 \% \mathrm{Cl} \text { ) }\end{array}$} \\
\hline & \multirow{2}{*}{$\begin{array}{l}\text { Screening } \\
11 / 3470\end{array}$} & \multirow{2}{*}{$\begin{array}{l}\text { Usual care } \\
84 / 18325\end{array}$} & & & & \\
\hline & & & & & 7.1 & 0.69 (0.37 to 1.30$)$ \\
\hline PLCO $55-59$ years & $40 / 13456$ & $55 / 13455$ & & & 14.6 & 0.73 (0.48 to 1.09$)$ \\
\hline SCORE $55-59$ years & $19 / 4767$ & $33 / 4751$ & & & 8.8 & 0.57 (0.33 to 1.01$)$ \\
\hline NORCCAP 55-59 years & $26 / 3619$ & $73 / 11259$ & & & 9.4 & 1.11 (0.71 to 1.73$)$ \\
\hline PLCO 60-64 years & $54 / 11771$ & $58 / 11756$ & & & 15.4 & 0.93 (0.64 to 1.35$)$ \\
\hline SCORE 60-64 years & $20 / 3802$ & $32 / 3731$ & & & 8.6 & 0.61 (0.35 to 1.07$)$ \\
\hline NORCCAP $60-64$ years & $25 / 3214$ & $96 / 9714$ & & & 12.7 & 0.79 (0.51 to 1.22$)$ \\
\hline PLCO 65-69 years & $35 / 8581$ & $58 / 8587$ & & & 15.4 & 0.60 (0.40 to 0.92$)$ \\
\hline PLCO 70-74 years & $21 / 5287$ & $30 / 5301$ & & & 8.0 & 0.70 (0.40 to 1.22$)$ \\
\hline Total $(95 \% \mathrm{Cl})$ & $251 / 57967$ & $519 / 86879$ & $<$ & & 100.0 & $0.76(0.65$ to 0.88$)$ \\
\hline \multicolumn{7}{|c|}{ Test for heterogeneity: $\chi^{2}=6.81, \mathrm{df}=8, \mathrm{P}=0.56, \mathrm{I}^{2}=0 \%$} \\
\hline \multirow{2}{*}{\multicolumn{3}{|c|}{ Test for overall effect: $z=3.56, P<0.001$}} & $0.5 \quad 0.7$ & 1.5 & 2 & \\
\hline & & & screening & $\begin{array}{r}\text { Favo } \\
\text { usual ca }\end{array}$ & & \\
\hline
\end{tabular}

Fig 3 | Colorectal cancer incidence in the distal colon (rectum and sigmoid colon) in women, based on data from the three trials comparing flexible sigmoidoscopy screening with usual care. $\mathrm{M}-\mathrm{H}=$ Mantel-Haenszel fixed effect model both comparisons). Screening reduced the incidence of proximal colorectal cancer by $35 \%$ in younger women (relative risk 0.65 ; 95\% confidence interval 0.50 to 0.84 ), while women aged 60 years and older did not benefit from screening (1.03; 0.88 to 1.20; table 2, figs 5 and 6 ). This finding was consistent in all three trials (fig 5).

In a sensitivity analysis, we included the descending colon in the definition of distal colon, and the results were comparable with those presented above: only 160 (3.8\%) of 4157 cases of colorectal cancer were located in the descending colon. In a second sensitivity analysis, we included procedural characteristics (compliance with screening, colonoscopy referral rate, bowel cleansing, and insertion depth of the endoscope at the screening examination) in univariate metaregression models, but none of these procedural characteristics was statistically significant. Thirdly, we included only individuals in the age group 55-64 years (the age range covered by all three trials, web table 3). Finally, we excluded the PLCO trial because of its large size compared with SCORE and NORCCAP. The results were comparable with the main analysis (web table 4, web figs 1 and 2).

To explore whether the difference in effectiveness of screening could be attributable to the distribution of colorectal cancer in the distal and proximal colon among men and women in different age groups, we used the control group (no screening) and calculated the proportion of colorectal cancers in the distal (rectosigmoid) colon compared with the proximal colon (fig 7). As shown, the proportion of distal versus proximal colorectal cancer was smaller for women than for men in all age groups. Proximal location of colorectal cancer occurs more frequently with increasing age. The distal/proximal ratio was about one in women aged 55-59, and less than one in those age 60 and over, while the same observation was made for men aged 70 and over.

\section{Colorectal cancer mortality}

A total of 373 individuals in the screening group and 740 in the usual care group died from colorectal cancer. The results from the meta-analysis are presented in table 2. Overall, colorectal cancer mortality was reduced by 27\% (relative risk $0.73 ; 95 \%$ confidence interval 0.64 to $0.83), 33 \%$ in men $(0.67 ; 95 \% 0.57$ to 0.80$)$, and $18 \%$ in women (0.82; 0.67 to $1.00, \mathrm{P}=0.048)$.

Screening reduced colorectal cancer mortality in the distal colon in men (relative risk 0.51; 95\% confidence interval 0.40 to 0.65 ), but not significantly in women ( $0.79 ; 0.58$ to 1.09$)$. There was no effect in either men or women on mortality from colorectal cancer due to proximal cancers (table 2). When the analyses were restricted to the 55-64 year age group, colorectal cancer mortality was statistically significantly reduced in men $(0.70 ; 0.57$ to 0.86$)$ and in younger women $(0.68 ; 0.47$ to 0.98 ), but not in women aged 60 years and older (1.07; 0.77 to 1.48 ; web table 5).

\section{Discussion}

Principal findings

To our knowledge, this is the first pooled analysis investigating the effect of flexible sigmoidoscopy screening 


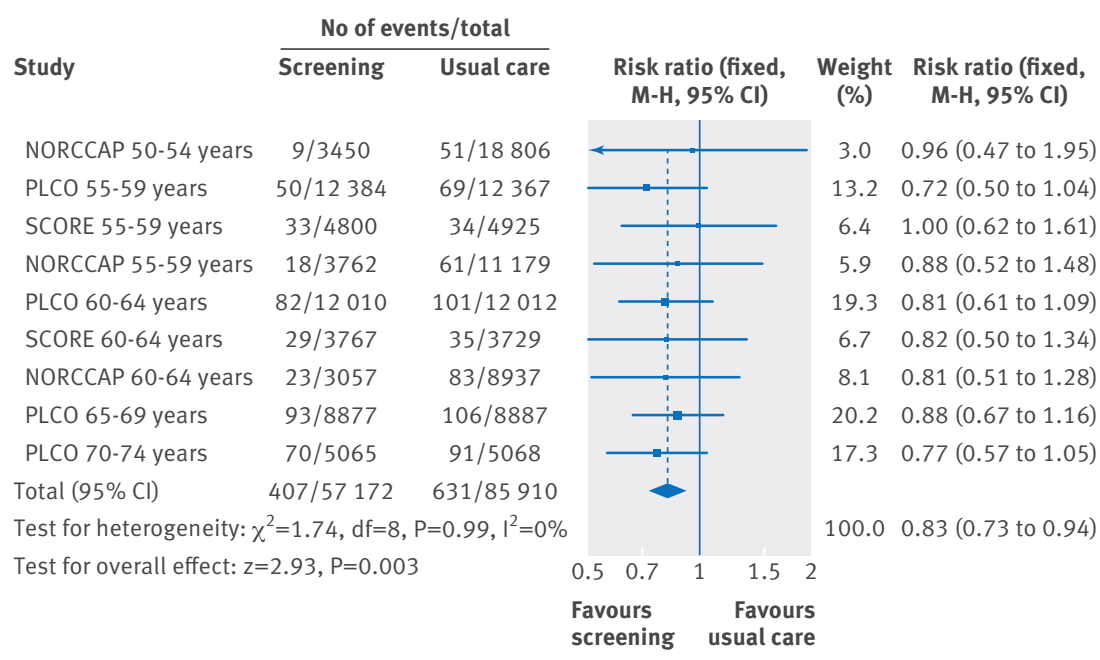

Fig 4 | Colorectal cancer incidence in the colon proximal to the sigmoid colon in men, based on data from the three trials comparing flexible sigmoidoscopy screening with usual care. $\mathrm{M}-\mathrm{H}=$ Mantel-Haenszel fixed effect model

by sex and age groups. Cooperation between our research groups enabled us to include aggregated data from almost 300000 individuals followed for 10 to 12 years. We found that flexible sigmoidoscopy is an effective screening tool in men. Incidence of colorectal cancer decreased by $24 \%$ and mortality by $33 \%$, regardless of age at screening. In women, the effect was smaller, and confined to women younger than 60 years.

The uniform effectiveness in the distal colon is expected, because this part is visualised during the screening examination. The effectiveness of screening in the proximal colon, however, depends on concomitant pathological findings in the distal and proximal colon. Several studies have found such an association, ${ }^{89}$ but others report that proximal advanced neoplasia without distal lesions are more common in women than in men, ${ }^{1011}$ which could explain why flexible sigmoidoscopy is less effective in women. Our results support this

\begin{tabular}{|c|c|c|c|c|c|c|}
\hline \multirow{3}{*}{$\begin{array}{l}\text { Study } \\
\text { NORCCAP 50-54 years }\end{array}$} & \multicolumn{2}{|c|}{ No of events/total } & \multirow{2}{*}{\multicolumn{2}{|c|}{$\begin{array}{l}\text { Risk ratio (fixed, } \\
\mathrm{M}-\mathrm{H}, 95 \% \mathrm{Cl} \text { ) }\end{array}$}} & \multirow{3}{*}{$\begin{array}{c}\text { Weight } \\
\text { (\%) } \\
4.3\end{array}$} & \multirow{3}{*}{$\begin{array}{l}\text { Risk ratio (fixed, } \\
\mathbf{M}-\mathbf{H}, \mathbf{9 5} \% \mathrm{Cl}) \\
0.67(0.32 \text { to } 1.40)\end{array}$} \\
\hline & \multirow{2}{*}{$\begin{array}{l}\text { Screening } \\
8 / 3470\end{array}$} & \multirow{2}{*}{$\begin{array}{l}\text { Usual care } \\
63 / 18325\end{array}$} & & & & \\
\hline & & & & & & \\
\hline PLCO 55-59 years & $40 / 13456$ & $67 / 13455$ & & & 14.5 & 0.60 (0.40 to 0.88$)$ \\
\hline SCORE $55-59$ years & $21 / 4767$ & $29 / 4751$ & & & 6.3 & $0.72(0.41$ to 1.26$)$ \\
\hline NORCCAP $55-59$ years & $15 / 3619$ & $68 / 11259$ & & & 7.2 & 0.69 (0.39 to 1.20$)$ \\
\hline PLCO 60-64 years & $95 / 11771$ & $88 / 11756$ & & & 19.1 & $1.08(0.81$ to 1.44$)$ \\
\hline SCORE 60-64 years & $24 / 3802$ & $21 / 3731$ & & & 4.6 & 1.12 (0.63 to 2.01$)$ \\
\hline NORCCAP $60-64$ years & $39 / 3214$ & $98 / 9714$ & & & 10.5 & $1.20(0.83$ to 1.74$)$ \\
\hline PLCO 65-69 years & $81 / 8581$ & $96 / 8587$ & & & 20.8 & 0.84 (0.63 to 1.13$)$ \\
\hline PLCO 70-74 years & $63 / 5287$ & $59 / 5301$ & & & 12.8 & 1.07 (0.75 to 1.52$)$ \\
\hline Total $(95 \% \mathrm{Cl})$ & $386 / 57967$ & $589 / 86879$ & - & & & \\
\hline \multicolumn{5}{|c|}{ Test for heterogeneity: $\chi^{2}=11.86, d f=8, P=0.16, I^{2}=33 \%$} & 100.0 & 0.91 (0.79 to 1.03 ) \\
\hline \multirow{2}{*}{\multicolumn{3}{|c|}{ Test for overall effect: $z=1.47, P=0.14$}} & $0.5 \quad 0.7$ & 1.5 & 2 & \\
\hline & & & $\begin{array}{l}\text { Favours } \\
\text { screening }\end{array}$ & $\begin{array}{r}\text { Favo } \\
\text { usual ca }\end{array}$ & & \\
\hline
\end{tabular}

Fig 5 Colorectal cancer incidence in the colon proximal to the sigmoid colon in women, based on data from the three trials comparing flexible sigmoidoscopy screening with usual care. $\mathrm{M}-\mathrm{H}=$ Mantel-Haenszel fixed effect model suggestion, but we also show that the smaller effect in women depends on age at screening.

In women younger than 60, flexible sigmoidoscopy screening reduces the incidence of colorectal cancer in the proximal colon, and in the sensitivity analyses for women aged 55-59 at screening, mortality was also reduced. The age difference in women might be due to technical issues with the procedures for sigmoidoscopy and subsequent colonoscopy (for those women who test positive at screening). Studies have identified greater difficulties in undertaking colonoscopies in women. ${ }^{1819}$ However, we found no large differences in performance or compliance (bowel cleansing, endoscope insertion depth, adherence to colonoscopy follow-up, caecum intubation rate) in older women compared with younger women (web table 1), and procedural characteristics were not statistically significant when they were tested in univariate meta regression models. More men than women were referred for colonoscopy due to findings at screening, which could explain the difference between the sexes in the proximal colon, but this cannot explain the age difference observed in women. This difference might be due to differences in the location of colorectal cancers in younger versus older women. As shown in figure 7, distal colorectal cancer is more frequent than proximal colorectal cancer in younger women, whereas after the age of 55-60, proximal colorectal cancer dominates. A similar trend is seen in men, but the shift from a higher proportion of distal to a higher proportion of proximal cancers occurs 10 years later than in women.

\section{Comparison with other studies}

Reports from several countries have shown similar findings, in addition to a temporal trend towards greater incidence of proximal colorectal cancer in recent decades, especially in women. ${ }^{12131520-23}$ This is unlikely to be the only explanation for the observed difference in sex and age, however. The ratio of distal to proximal cancers is only marginally different in women between the age ranges of 55-59 and 60-64 (fig 7), while there seems to be a change in the effectiveness of flexible sigmoidoscopy screening at around age 60.

In recent years, it has become evident that colorectal cancer is a heterogeneous disease. Current screening strategies focus on the detection of adenomas, but adenomas-through the adenoma-carcinoma sequence ${ }^{2425}$-is only one of the precursors to colorectal cancer. About $16 \%$ of colorectal cancers develop through the serrated pathway, with the sessile serrated adenoma or polyp (SSA/P) as the precursor lesion. ${ }^{26}$ These lesions are most often proximal, and in one study, $52 \%$ of individuals with advanced proximal serrated polyps (defined as $\mathrm{SSA} / \mathrm{P} \geq 10 \mathrm{~mm}$ with dysplastic features, or traditional serrated adenomas) did not have a distal lesion that could be detected at flexible sigmoidoscopy and which would trigger a full colonoscopy. ${ }^{7}$ In the same study, distal adenomas were associated with proximal adenomas, but not with proximal advanced serrated lesions. Thus, flexible sigmoidoscopy could be inadequate in detecting these polyps. 


\begin{tabular}{|c|c|c|c|c|}
\hline & \multicolumn{4}{|c|}{ Screening group $v$ control group } \\
\hline & $\begin{array}{l}\text { Colorectal cancer } \\
\text { incidence (relative } \\
\text { risk }(95 \% \mathrm{CI}))\end{array}$ & $\begin{array}{l}\mathrm{P} \text { for } \\
\text { interaction }\end{array}$ & $\begin{array}{l}\text { Colorectal cancer } \\
\text { mortality (relative } \\
\text { risk }(95 \% \mathrm{CI}))\end{array}$ & $\begin{array}{l}\text { P for } \\
\text { interaction }\end{array}$ \\
\hline \multicolumn{5}{|c|}{ Colon and rectum } \\
\hline Both sexes* & $0.79(0.74$ to 0.84$)$ & \multirow{7}{*}{0.12} & $0.73(0.64$ to 0.83$)$ & \multirow{7}{*}{0.55} \\
\hline Ment & $0.76(0.70$ to 0.83$)$ & & 0.67 (0.57 to 0.80$)$ & \\
\hline$\geq 60$ years $\ddagger$ & $0.76(0.68$ to 0.84$)$ & & $0.67(0.55$ to 0.82$)$ & \\
\hline$<60$ years§ & $0.76(0.65$ to 0.88$)$ & & $0.67(0.49$ to 0.91$)$ & \\
\hline Women & $0.83(0.75$ to 0.92$)$ & & $0.82(0.67$ to 1.00$)$ & \\
\hline$\geq 60$ years $\ddagger$ & $0.90(0.80$ to 1.02$)$ & & 0.88 (0.69 to 1.12$)$ & \\
\hline$<60$ years§ & $0.71(0.59$ to 0.84$)$ & & $0.73(0.53$ to 1.02$)$ & \\
\hline \multicolumn{5}{|l|}{ Distal colon } \\
\hline Both sexes* & $0.73(0.66$ to 0.80$)$ & \multirow{7}{*}{0.66} & $0.60(0.49$ to 0.72$)$ & \multirow{7}{*}{0.39} \\
\hline Ment & 0.71 (0.63 to 0.80$)$ & & 0.51 (0.40 to 0.65$)$ & \\
\hline$\geq 60$ years $\ddagger$ & $0.72(0.62$ to 0.84$)$ & & $0.48(0.35$ to 0.64$)$ & \\
\hline$<60$ yearsई & 0.69 (0.56 to 0.85$)$ & & $0.58(0.38$ to 0.90$)$ & \\
\hline Women & $0.76(0.65$ to 0.88$)$ & & 0.79 (0.58 to 1.09) & \\
\hline$\geq 60$ years $\ddagger$ & 0.74 (0.61 to 0.91$)$ & & $0.85(0.57$ to 1.27$)$ & \\
\hline$<60$ years§ & 0.78 (0.61 to 0.99$)$ & & 0.71 (0.42 to 1.18$)$ & \\
\hline \multicolumn{5}{|c|}{ Proximal colon } \\
\hline Both sexes* & $0.86(0.79$ to 0.93$)$ & \multirow{7}{*}{0.04} & $0.87(0.73$ to 1.04$)$ & \multirow{7}{*}{0.61} \\
\hline Ment & 0.83 (0.73 to 0.94) & & 0.89 (0.70 to 1.13) & \\
\hline$\geq 60$ years $\ddagger$ & $0.82(0.71$ to 0.95$)$ & & $0.96(0.73$ to 1.28$)$ & \\
\hline$<60$ years§ & 0.84 (0.66 to 1.07) & & $0.71(0.44$ to 1.14$)$ & \\
\hline Womenף & 0.91 (0.79 to 1.03) & & 0.85 (0.66 to 1.10$)$ & \\
\hline$\geq 60$ years $\ddagger$ & $1.03(0.88$ to 1.20$)$ & & 0.89 (0.65 to 1.21$)$ & \\
\hline$<60$ years§ & 0.65 (0.50 to 0.84$)$ & & 0.79 (0.51 to 1.23) & \\
\hline \multicolumn{5}{|c|}{$\begin{array}{l}\text { Distal colon=rectum and sigmoid; proximal colon=colon proximal to the sigmoid descending junction. } \\
\text { *Screening group versus control group, no stratification. } \\
\text { †Screening group versus control group, men only, no age stratification. } \\
\text { ¥Screening group versus control group, stratification by sex, participants aged 60-74. } \\
\S S c r e e n i n g \text { group versus control group, stratification by sex, participants aged 50-59. } \\
\text { १Screening group versus control group, women only, no age stratification. }\end{array}$} \\
\hline
\end{tabular}

Risk factors for adenomas and serrated polyps might differ between men and women and could be important when flexible sigmoidoscopy is considered as a screening tool. ${ }^{27}$ Being male is a well established risk factor for adenomas, but the evidence for sex as a risk factor for $\mathrm{SSA} / \mathrm{P}$ is limited and conflicting. ${ }^{28-30}$ Some reports have found that being female is an independent risk factor for SSA/P, but others have not confirmed this finding. ${ }^{2731}$ There is unlikely to be a male predominance for SSA/P, however. Advancing age is probably also a risk factor for SSA/P, as it is for adenomas. ${ }^{2728}$ Thus, with increasing age, proximal SSA/P and proximal adenomas become more prevalent. A considerable proportion of these proximal polyps might not have a distal lesion that could trigger a full colonoscopy. The proportion without a distal adenoma might be more pronounced in women than men and could explain the difference that we observe in women in the present pooled analysis.

The analysis of colorectal cancer mortality is more difficult to interpret. The number of deaths are few and the confidence intervals wide when the data is stratified in subgroups. This could explain why the point estimates for death due to proximal colorectal cancer seem discordant with those for proximal colorectal cancer incidence. Flexible sigmoidoscopy screening reduces the incidence of colorectal cancer and mortality via polypectomy, which prevents incidence of colorectal cancer and results in fewer tumours being at risk for causing death due to colorectal cancer. Flexible sigmoidoscopy also reduces mortality via early detection, because screen detected tumours have a more favourable prognosis. An interesting finding is illustrated in figure 6. Cancers detected through screening are almost exclusively located in the distal colon, as evident from the starting points of the curves. Possible explanations are that the proximal colon is not visualised in most screening participants, that distal polyps are poor predictors of synchronous proximal colorectal cancer, and that few proximal colorectal cancers were prevalent at the time of sigmoidoscopy screening. Because few proximal cancers were detected early at screening, any screening effect in the proximal colon needs to be mediated through prevention, and not by early detection.

\section{Strengths and limitations of study}

Strengths of this study include the large number of individuals and consistent results between trials, with no heterogeneity in the stratified analyses, but there are several limitations. Firstly, the statistical test for heterogeneity has limited power to detect differences between trials when the number of studies is small. ${ }^{32}$ Secondly, the PLCO trial is larger than the other two trials and includes older individuals ( $>65$ years), which could create bias. For example, in the screening group, $79 \%$ of individuals 60 years or older were recruited from the PLCO trial, which might limit the generalisability of the results. Results from the sensitivity analyses do not support the existence of such a bias, however. In the analyses restricted to the 55-64 year age group from all three trials, and in analyses restricted to SCORE and NORCCAP only, the results were comparable with the main findings (supplementary material).

Thirdly, even if our findings were consistent across the three trials and the numbers are large and of high statistical precision, we would appreciate validation in independent samples. The only available data source for validation is the UK Flexi Scope trial, which would have added 50\% more individuals to the pooled screening group and might have affected our results. ${ }^{2}$ In the UK trial, however, proximal colorectal cancer incidence rates were almost identical in the group that was screened and the group that received usual care, probably due to the low rate of colonoscopy referrals (5\%), compared with the three other trials (8.8-21.9\%). ${ }^{2-5}$ Inclusion of the UK trial in the present pooled analysis might thus have obscured the difference in sex and age with regards to the proximal colon, because few participants had visualisation of the proximal large bowel. ${ }^{2}$ Finally, even if almost 300000 individuals were included in our pooled analysis, there were no statistically significant differences between men and women in any age group, and the results should be interpreted with this in mind. However, almost 72000 women were 60 years and older, of whom 662 were diagnosed with 
Fig 6 | Cumulative proportion of individuals diagnosed with distal (rectosigmoid) and proximal (oral to the descending sigmoid junction) colorectal cancer in PLCO, SCORE, and NORCCAP trials comparing flexible sigmoidoscopy screening with usual care
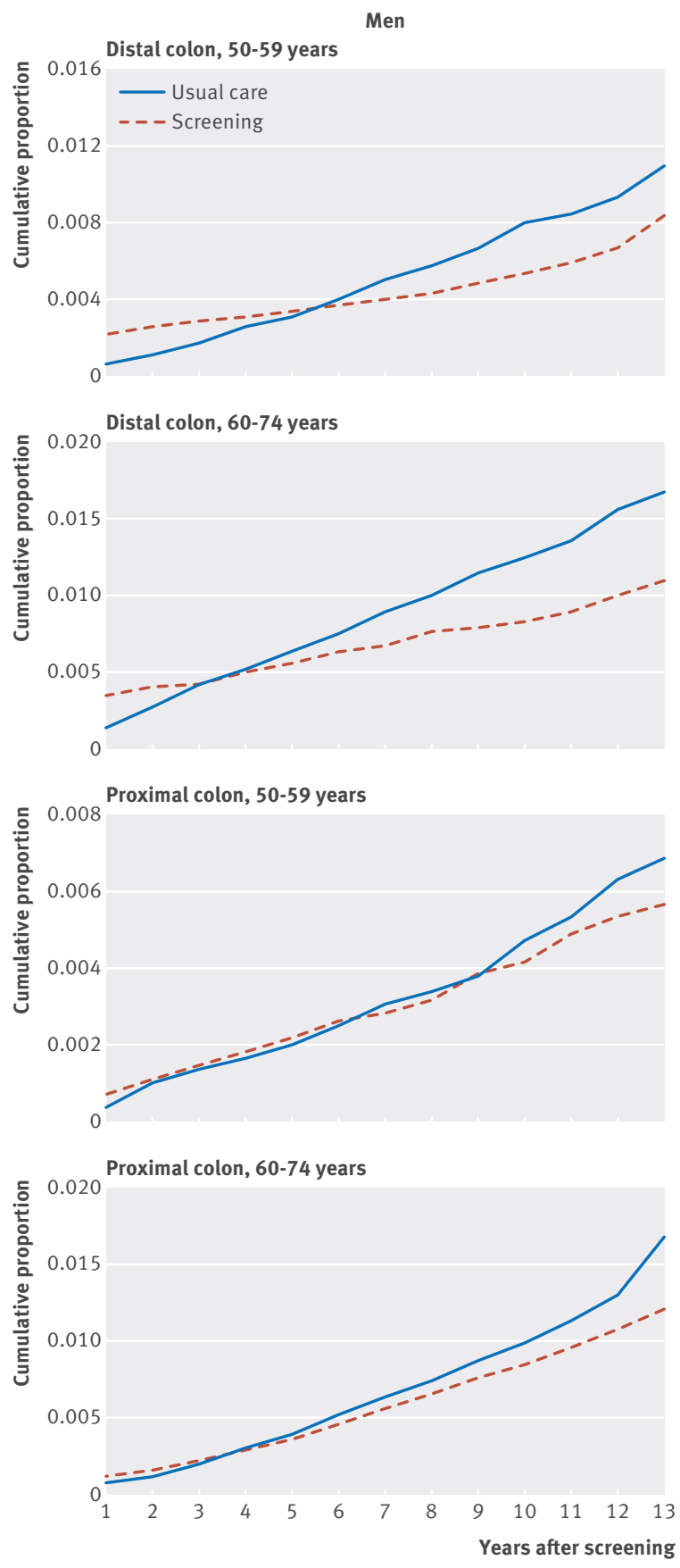

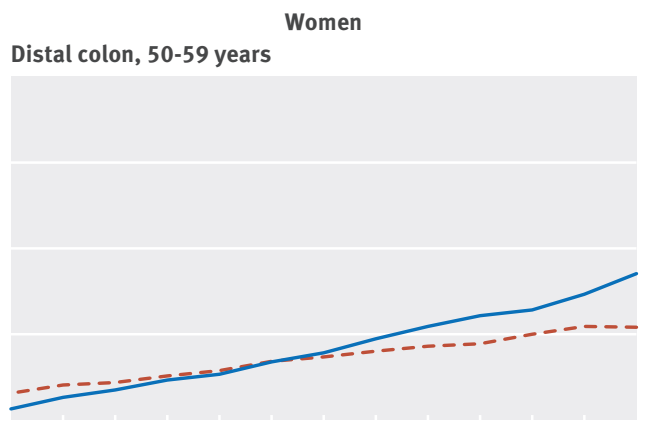

Distal colon, 60-74 years

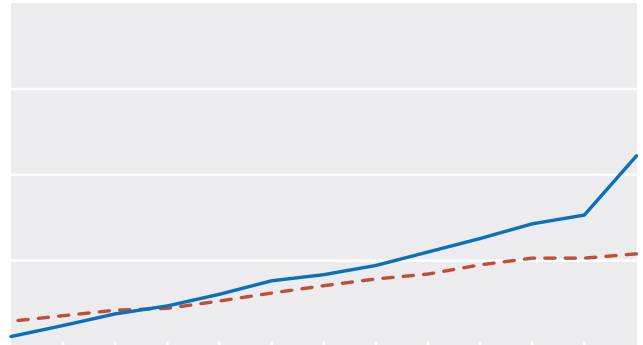

Proximal colon, 50-59 years

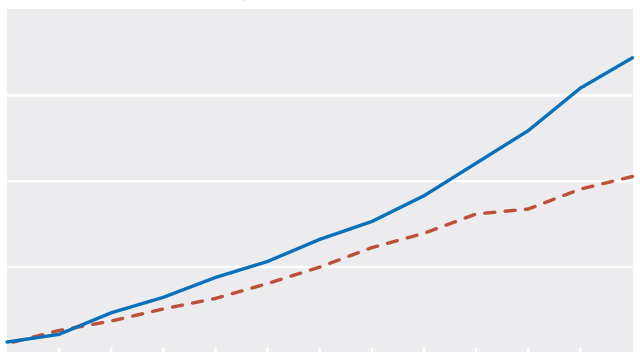

Proximal colon, 60-74 years

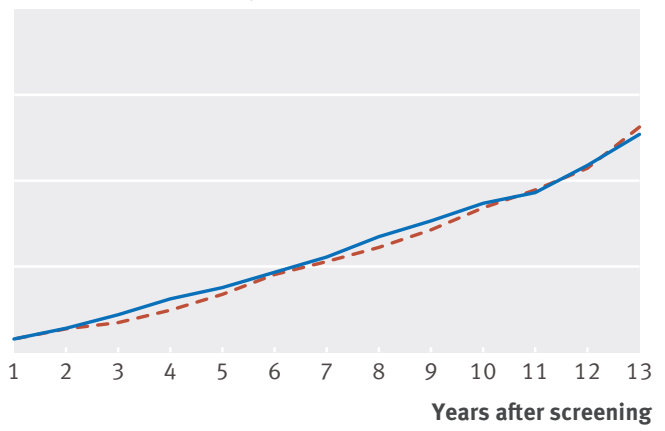

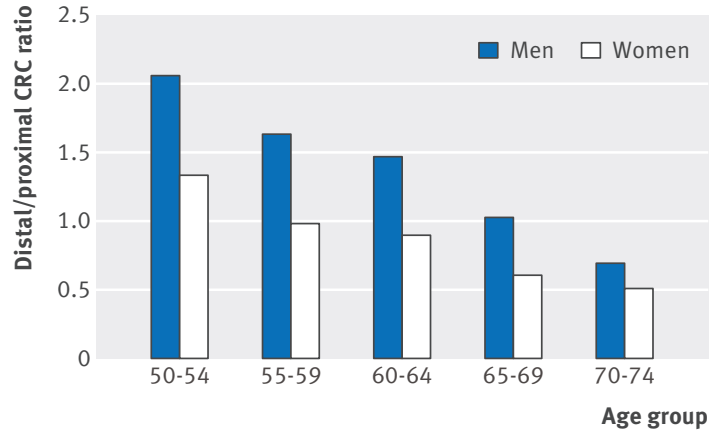

Fig 7 | Proportion of colorectal cancer (CRC) cases among men and women in the distal (rectosigmoid) and proximal colon (oral to the descending sigmoid junction) in the usual care groups in PLCO, SCORE, and NORCCAP trials. The age group indicates age at screening, and the distal/proximal ratio is calculated for the entire follow-up (median 10.5-11.9 years) proximal colorectal cancer. Not at any point since randomisation was there any difference between the screening group and the control group (fig 6).

\section{Conclusion and policy implications}

Currently, screening recommendations for colorectal cancer are similar for men and women, both with respect to screening modality and screening age. Our results could serve as a basis for more individualised recommendations determined by the age and sex of those eligible for screening. The idea of screening recommendations that are specific to these categories, however, raises concerns about acceptability in the population and also whether different life expectancy between men and women should be taken into account. 
Most important is to offer a screening programme that indeed reduces colorectal cancer morbidity. According to our findings, flexible sigmoidoscopy is a valid screening option for men and younger women, but is not as effective for women aged 60 years and older. Whether other screening tools to more effectively detect proximal tumours-such as colonoscopy or the faecal occult blood test-offer a better alternative for older women is currently unknown and warrants further investigation. We thank Jan Odgaard-Jensen at the Norwegian Knowledge Center for the Health Services for assistance with statistical analyses.

Contributors: All authors had access to all data and take responsibility for the integrity of the data. All authors contributed to the study concept and design; the acquisition, analysis, and interpretation of data; and the critical revision of the manuscript for important intellectual content. $\varnothing \mathrm{H}$ performed the statistical analyses and takes responsibility for the accuracy of the data analyses (guarantor), drafting of the manuscript, statistical analysis, and funding obtained. Study supervision was by GH, RES, and CS.

Funding: The present work was funded by a postdoctoral grant from South-Eastern Norway Regional Health Authorities and by Sorlandet Hospital Kristiansand, Norway.

Competing interests: All authors have completed the ICMJE uniform disclosure form at www.icmje.org/coi_disclosure.pdf and declare: support from South-Eastern Norway Regional Health Authorities and by Sorlandet Hospital Kristiansand for the submitted work; no financial relationships with any organisations that might have an interest in the submitted work in the previous three years; no other relationships or activities that could appear to have influenced the submitted work.

Ethical approval: No ethical approval for the pooled analysis was required. Patients provided written, informed consent in the context of each trial (only screening attenders in NORCCAP). No new consent was obtained for the pooled analysis.

Data sharing: Data are available from the principal investigators of the individual trials on request.

The lead author affirms that the manuscript is an honest, accurate, and transparent account of the study being reported; that no important aspects of the study have been omitted; and that any discrepancies from the study as planned (and, if relevant, registered) have been explained.

This is an Open Access article distributed in accordance with the Creative Commons Attribution Non Commercial (CC BY-NC 3.0) license, which permits others to distribute, remix, adapt, build upon this work non-commercially, and license their derivative works on different terms, provided the original work is properly cited and the use is noncommercial. See: http://creativecommons.org/licenses/by-nc/3.0/.

1 Ferlay J, Soerjomataram I, Ervik M, et al. GLOBOCAN 2012 v1.0, Cancer Incidence and Mortality Worldwide: IARC CancerBase No 11. International Agency for Research on Cancer; 2013. http:// globocan.iarc.fr/Pages/online.aspx.

2 Atkin WS, Edwards R, Kralj-Hans I, et al. UK Flexible Sigmoidoscopy Trial Investigators. Once-only flexible sigmoidoscopy screening in prevention of colorectal cancer: a multicentre randomised controlled trial. Lancet 2010;375:1624-33. doi:10.1016/

S0140-6736(10)60551-X

3 Holme $\emptyset$, Løberg M, Kalager M, et al. Effect of flexible sigmoidoscopy screening on colorectal cancer incidence and mortality: a randomized clinical trial. JAMA 2014;312:606-15. doi:10.1001/jama.2014.8266.

4 Schoen RE, Pinsky PF, Weissfeld JL, et al. PLCO Project Team. Colorectal-cancer incidence and mortality with screening flexible sigmoidoscopy. N Engl J Med 2012;366:2345-57. doi:10.1056/ NEJMoa1114635.

5 Segnan N, Armaroli P, Bonelli L, et al. SCORE Working Group. Once-only sigmoidoscopy in colorectal cancer screening: follow-up findings of the Italian Randomized Controlled Trial-SCORE [correction in: J Natl Cancer Inst 2011;103:1903]. J Natl Cancer Inst 2011;103:1310-22. doi:10.1093/inci/dir284.

6 Elmunzer BJ, Hayward RA, Schoenfeld PS, Saini SD, Deshpande A, Waljee AK. Effect of flexible sigmoidoscopy-based screening on incidence and mortality of colorectal cancer: a systematic review and meta-analysis of randomized controlled trials. PLOS Med 2012;9:e1001352. doi:10.1371/journal.pmed.1001352

7 Kahi CJ, Vemulapalli KC, Snover DC, Abdel Jawad KH, Cummings OW, Rex DK. Findings in the distal colorectum are not associated with proximal advanced serrated lesions. Clin Gastroenterol Hepatol 2015;13:345-51. doi:10.1016/j.cgh.2014.07.044
8 Lieberman DA, Weiss DG, Bond JH, Ahnen DJ, Garewal H, Chejfec G. Use of colonoscopy to screen asymptomatic adults for colorectal cancer. Veterans Affairs Cooperative Study Group 380. N Engl J Med 2000;343:162-8. doi:10.1056/NEJM200007203430301.

9 Pinsky PF, Schoen RE, Weissfeld JL, Bresalier RS, Hayes RB, Gohagan JK. Predictors of advanced proximal neoplasia in persons with abnormal screening flexible sigmoidoscopy. Clin Gastroenterol Hepatol 2003;1:103-10. doi:10.1053/cgh.2003.50017.

10 Schoenfeld P, Cash B, Flood A, et al. CONCeRN Study Investigators. Colonoscopic screening of average-risk women for colorectal neoplasia. N Engl J Med 2005;352:2061-8. doi:10.1056/ NEJMoa042990.

11 Forsberg AM, Kjellström L, Agréus L, et al. Prevalence of colonic neoplasia and advanced lesions in the normal population: a prospective population-based colonoscopy study. Scand ) Gastroenterol 2012;47:184-90. doi:10.3109/00365521.2011.647062.

12 Larsen IK, Bray F. Trends in colorectal cancer incidence in Norway 1962-2006: an interpretation of the temporal patterns by anatomic subsite. Int J Cancer 2010;126:721-32. doi:10.1002/ijc.24839.

13 Shah AB, Sarfati D, Blakely T, Atkinson J, Dennett ER. Trends in colorectal cancer incidence rates in New Zealand, 1981-2004. ANZ J Surg 2012;82:258-64. doi:10.1111/j.1445-2197.2011.05995.x.

14 Caldarella A, Crocetti E, Messerini L, Paci E. Trends in colorectal incidence by anatomic subsite from 1985 to 2005: a populationbased study. Int J Colorectal Dis 2013;28:637-41. doi:10.1007/ s00384-013-1672-2.

15 Saltzstein SL, Behling CA. Age and time as factors in the left-to-right shift of the subsite of colorectal adenocarcinoma: a study of 213,383 cases from the California Cancer Registry. J Clin Gastroenterol 2007:41:173-7. doi:10.1097/01.mcg.0000225550.26751.6a.

16 Higgins JP, Green S, eds. Cochrane Handbook for Systematic Reviews of Interventions. Version 5.1.0 [updated March 2011]: The Cochrane Collaboration, 2011. http://www.cochrane-handbook.org.

17 Harbord RM, Higgins IPT. Meta-regression in Stata. Stata 2008;8:493-519.

18 Saunders BP, Fukumoto M, Halligan S, et al. Why is colonoscopy more difficult in women?Gastrointest Endosc 1996;43:124-6. doi:10.1016/ S0016-5107(06)80113-6.

19 Holme O, Bretthauer M, de Lange T, et al. Risk stratification to predict pain during unsedated colonoscopy: results of a multicenter cohort study. Endoscopy 2013:45:691-6. doi:10.1055/s-0033-1344239.

20 Benedix F, Kube R, Meyer F, Schmidt U, Gastinger I, Lippert H. Colon/ Rectum Carcinomas (Primary Tumor) Study Group. Comparison of 17,641 patients with right- and left-sided colon cancer: differences in epidemiology, perioperative course, histology, and survival. Dis Colon Rectum 2010;53:57-64. doi:10.1007/DCR.0b013e3181c703a4

21 Maruta M, Kotake K, Maeda K. Colorectal cancer in Japan. Rozhl Chir 2007:86:618-21.

22 lacopetta B. Are there two sides to colorectal cancer?/nt/ Cancer 2002;101:403-8. doi:10.1002/ijc.10635.

23 Nawa T, Kato J, Kawamoto H, et al. Differences between right- and left-sided colon cancer in patient characteristics, cancer morphology and histology. J Gastroenterol Hepatol 2008;23:418-23. doi:10.1111/j.1440-1746.2007.04923x.

24 Vogelstein B, Fearon ER, Hamilton SR, et al. Genetic alterations during colorectal-tumor development. N Engl J Med 1988;319:525-32. doi:10.1056/NEJM198809013190901.

25 Muto T, Bussey HJ, Morson BC. The evolution of cancer of the colon and rectum. Cancer 1975;36:2251-70. doi:10.1002/cncr.2820360944.

26 Nishihara R, Wu K, Lochhead P, et al. Long-term colorectal-cancer incidence and mortality after lower endoscopy. N Engl J Med 2013;369:1095-105. doi:10.1056/NEJMoa1301969.

27 Haque TR, Bradshaw PT, Crockett SD. Risk factors for serrated polyps of the colorectum. Dig Dis Sci 2014;59:2874-89. doi:10.1007/ s10620-014-3277-1.

28 Corley DA, Levin TR, Doubeni CA. Adenoma detection rate and risk of colorectal cancer and death. N Engl / Med 2014;370:1298. doi:10.1056/NEJMoa1309086.

29 Leaper M, Johnston MJ, Barclay M, Dobbs BR, Frizelle FA. Reasons for failure to diagnose colorectal carcinoma at colonoscopy. Endoscopy 2004;36:499-503. doi:10.1055/s-2004-814399.

30 Schoen RE, Pinsky PF, Weissfeld JL, et al. Prostate, Lung, Colorectal, and Ovarian Cancer Screening Trial Group. Results of repeat sigmoidoscopy 3 years after a negative examination. JAMA 2003;290:41-8.

31 Rex DK, Ahnen DJ, Baron JA, et al. Serrated lesions of the colorectum: review and recommendations from an expert panel. Am J Gastroenterol 2012;107:1315-29, quiz 1314, 1330. doi:10.1038/ ajg.2012.161.

32 von Hippel PT. The heterogeneity statistic I(2) can be biased in small meta-analyses. BMC Med Res Methodol 2015;15:35. doi:10.1186/ s12874-015-0024-z.

Appendix: Supplementary material 